REVISTA INTERNACIONAL DE CIENCIAS DEL DEPORTE International Journal of Sport Science

Rev. int. cienc. deporte

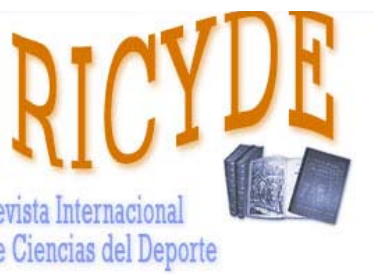

International Journal of Sport Science VOLUMEN IX - AÑO IX

Páginas:48-59 ISSN:1885-3137

No 31 - Enero - 2013

\title{
The effects of task organization on skill and knowledge in physical education Efecto de la forma de organización sobre el aprendizaje técnico y conceptual en educación física
}

\author{
Antonio Calderón \\ Universidad Católica San Antonio de Murcia, España \\ Peter Andrew Hastie \\ Universidad de Auburn, Estados Unidos \\ Jose Manuel Palao y Enrique Ortega \\ Universidad de Murcia, España
}

\begin{abstract}
The study examined the effects of different methods of practice three track and field skills (hurdles, high jump and shot put) on students performance, from both qualitative (systematic observation), and quantitative (time, height, and distance) perspectives, and also their knowledge of the events. One hundred and twenty-two students ( 71 boys and 51 girls of $13.4 \pm 1.2$ years) from a high school participated in nine lessons in which they used three different types organization of practice. Results show that the organization of practice had a significant effect on performance for lower and medium skill level students, but improvements differed across events. For example, students made significant improvements in shot put when practicing in lines, and for hurdles when practiced in games. These results reinforce the idea that is important for physical education teachers these variables when planning lessons.
\end{abstract}

Key words: athletics; tasks; skill; task organization; physical education; knowledge.

\section{Resumen}

El estudio examinó el efecto de tres formas de organización (filas, circuitos y juegos) sobre el aprendizaje técnico y conceptual de tres habilidades atléticas (vallas, salto de altura y lanzamiento de peso). Ciento veinte y dos estudiantes (71 chicos y 51 chicas de 13,4 $\pm 1,2$ años) de Educación Secundaria, participaron en nueve sesiones de enseñanza-aprendizaje durante la clase de educación física, en las que se utilizaron los tres tipos de organización de la práctica. Los resultados muestran que el tipo de organización tuvo un efecto significativo sobre el aprendizaje técnico y conceptual, en alumnos con nivel de habilidad bajo y medio, aunque con diferencias entre las disciplinas. Así por ejemplo, los alumnos mejoraron significativamente en lanzamiento de peso cuando practicaron en filas, y en vallas cuando practicaron en juegos. Estos resultados refuerzan por tanto la idea que es estas variables deben ser tenidas en consideración por los profesores de educación física cuando planifican sus sesiones.

Palabras clave: atletismo; tareas; formas de organización; nivel de habilidad; educación física; conocimiento.

Correspondence/correspondencia: Antonio Calderón Luquin

Universidad Católica San Antonio de Murcia, España

E-mail: acluquin@ucam.edu 


\section{Introduction}

$\mathrm{R}^{\mathrm{s}}$ esearch on teaching physical education has provided a significant amount of knowledge about how structuring practice and the provision of learning opportunities (Metzler, 2005; Siedentop \& Tannehill, 1999; Rink, 2005; Silverman, 2005). Official physical education curricula usually prescribe content and achievement indicators for motor skill learning, and for the learning knowledge about the concepts of those skills. With regard to skill learning, one of the most studied variables within physical education research has been task organization (Silverman, Tyson, \& Marrs, 1988; Silverman, Kulinna, \& Crull, 1995). The general findings of these studies indicates that it is important to organize tasks in order to allow students to accumulate high quality repetitions, as this has been shown to correlate with improvements in skill learning (Rink, 2003). As Silverman (2005) pointed out, the most important variables that impact skill learning, while not working in isolation (Silverman et al., 1988, 1995), are time and organization, practice, communication, class size, student attitude, and appropriate student practice.

According to Renshaw, Chow, Davids, \& Hammond (2010), in order to design appropriate environments for performance and learning of movement skills, physical educators need a sound theoretical model of the learner and of processes of learning. In physical education, this type of modelling informs the organisation of learning environments and effective and efficient use of practice time. Modelling how learners acquire functional movement patterns is essential for considering practical issues such as: (1) selecting ergonomically designed equipment for each learner; (2) organising and structuring learning environments and teaching tasks; (3) planning and management of exercise and practice programmes; (4) prevention of injury and associated health and safety considerations; and (5) understanding the nature of individual differences at various levels of performance.

With regard to task organization, Silverman, Mays, \& Subramaniam (1998), Silverman et al. (1995), and Silverman et al. (1988), identified individual practice, reciprocal practice, small and large group practice (paired group practice, small group practice, group practice), and gameactivities (lead-up games, scrimmages, and games) as possible arrangements. These studies also reported that in individual practice students executed a higher number of high quality repetitions when compared with group practice and game activities, suggesting it may be a superior way to organize and practice the task.

However, the studies mentioned above focused more on the context of team sports. To date, few if any studies have addressed task organization in individual sports. Across all studies, however, both in terms of team and individual sports, there is a lack of research that relates specifically to the relationship between task organization and learning, particularly in the development of content knowledge. This study examined the relationship between three forms of task organization (lines, circuits, and game activities) on the skill and knowledge development of three track and field skills within physical education.

Others studies from the motor learning research analyzed different domains in deep relation with task organization. The first area of interest, is called "variability of practice” (Moxley, 1979). Evidence on this area has shown that this has a peculiar effect on learning skills (Barreiros, Figuereido, \& Godinho, 2007). In some open tasks the variability of practice did promote better retention and transfer, but this was not the case for the most closed tasks. As Barreiros et al. (2007) argued, the variability of practice effect depended on a number of variables: amount of practice, intertrial interval, task characteristics, sources of variability, level of expertise, distribution of practice, etc. In relation with the distribution of practice, the literature shown that the manner in which practice is conducted, seems to influence 
performance at a later time (Russell \& Newell, 2007). At this point, practice sequences of trials could be structured under either a blocked (blocked practice) or a random (random practice) practice schedule. According to Russell \& Newell (2007), the perfoming results in blocked practice is better than in random practice, but these results changes in the retention test. Many authors termed this phenomenon the contextual interference effect, which is low in blocked practice (enhances acquisition performance but minimizes learning over the time), and high in random practice (degrades performance during practice but enhances learning over the time).

This study was designed with respects to a number of key factors outlined in Silverman's (1994) research on teaching and student achievement. First, the study took place in a real life gymnasium, and actual achievement measures were used. Second, as interactions of various students' characteristics such as gender and skill level have been posited as having an impact on learning, the results of this study are compared across students with different skill levels. Based on the literature review it is expected that, practicing in lines should I allow students to accumulate high quality repetitions (and fewer when practicing in circuits) so increases in skill and concept learning should be higher than circuits and game activities.

\section{Method}

\section{Participants}

The participants in this study were 122 students (71 boys and 51 girls) from six physical education classes in one secondary school in the south of Spain. These students were from eight different classes in the either the first or third course, the equivalent ages being 12 and 14 (13.4 \pm 1.2 years old).

The classes were taught by two licensed teachers of physical activity and sport science, with 10 and 20 years of experience. Both teachers took part in an orientation process before the practical intervention commenced. This process consisted of six meetings in which the theoretical aspects, the tasks and tests that would be used, and the practical aspects related to the units were explained and standardized. First, they were evaluated to designed a specific program of action. It mainly consisted in the analysis of sample lessons and sample technique videos (Human Kinetics, 1999a; Human Kinetics 1999b), and photosequences (Piasenta, 2000). Second, this, they practiced the three events with the different conditions (lines, circuits, and game activities). Last, they were evaluated again (analysis of students' skill performances to give feedback) to confirm the acquired the specific content knowledge.

Approval for the study was gained from all relevant parties, including the city council's Education Council, the school's administration, Pedagogical Commission (made up of all of the school's department chairs), and Department of Physical Education, as well as the School Board (represented by administration, teachers, parents, and students), the Parent Teacher Association, and from the parents of the students that took part in the study.

\section{Procedures}

Six of the eight classes in the study took part in nine lessons of track and field athletics in which the focus was the development of skills and knowledge in three events. These were the hurdles, high jump, and shot put (representing one run, one jump, and one throw). Classes were scheduled for 50 minutes, twice per week. All lessons were recorded on videotape, and all students wore a numbered mesh jersey. The other two classes (one from each course) were considered as control groups, and participated in an equal number of lessons, one course did basketball and the other did volleyball using direct instruction. To verify the treatment the 
main researcher was always present in all the classes to resolve any doubt, and to advise the teachers every time the need. Teachers were also given a guide in which they could see of every exercise, short explication, goals, key technique aspects (to give feedback), key organizational aspects, and a representation of all (drawing).

For each course level, three classes were randomly assigned to one of three conditions. These were (i) group practice in lines, (ii) group practice using circuits, and (iii) practice in game activities.

Group practice in lines. In this arrangement, three lines of 8-10 students were used. The exercise repetitions for this organization were alternating, three students (one from each line) at a time. The instructor was located at the side of the group to clearly observe the repetitions and correct students. An example of the first exercise for high jump was to do an approach of five steps and then make the take off of a scissor jump from inside a hoop.

Group practice using circuits. The students rotated through five students in groups of between five and seven students at each station. The instructor rotated through the stations in order to provide feedback to the students. In circuits, this exercise was performed in the same way. The only difference was that the students practiced in stations, particularly, in station number two of the circuit.

Group practice through game activities. This involved the simultaneous participation of the whole class in a series of teacher-directed games that required them to practice the same skills that were practiced in lines and circuits were used. In games activities, it was a little bit difference and difficult, because it was to be designed a game, in which the main goal was to perform a scissor jump with the same characteristics described before. To do that, we work collaboratively with an expert in designed games. In the designed game, the students work in two groups, there were two restricted areas with two thick mats (to land). The students of one team, to get one point had to run from one area to the other without being touch, and then perform the scissor jump described (five approach and take-off inside a hoop).

\section{Data collection}

Data were collected to assess the students' skills and knowledge at three points during the study. These were (i) before the commencement of the intervention (pre-test), (ii) at the completion of the intervention (post-test), and (iii) three weeks following the intervention (retest).

Skill tests. With regard to skill learning both quantitative (execution) aspects and qualitative (technique) aspects were evaluated. Three measures of skill execution were obtained. The first was the time taken to run $40 \mathrm{~m}$ and clear three hurdles (between 0.65 and $0.80 \mathrm{~m}$ high, and 6.50 and $7.50 \mathrm{~m}$ between hurdles) from a standing start after an auditory signal by the teacher. The second was the success or not of clearance with a "fosbury flop" at a specified height with a five step approach ( 0.90 and $1.10 \mathrm{~m}$ for low and high skill level students of first course, and 1.10 and $1.30 \mathrm{~m}$ for low and high skill level students of third grade level, respectively). The third, was the horizontal distance obtained in an outdoor adaptation of the glide shot put technique (double-lateral step and throw), with different weights and dimensions (of two, three and four kg for each course).. The throw was executed from a delimited circle of one meter radius. These tests used were previously developed in a pilot study, with 12-14 yearolds (Calderón, Palao, \& Ortega, 2005), and found to provide accurate measures of student performance for this age group.

Technical performance. To assess the students' technical development, two observers were trained to qualitatively evaluate various aspects of their performances. Following the 
recommendations of Behar (1993), the training of these observers consisted of (i) a theoretical explanation of the study variables (key technique aspects of each event evaluated) and coding rules (are the key aspects performed correctly?), for which an instruction manual was designed (ii) training in the scoring of the variables and (iii) live practice training in physical education lessons. In a example, the key aspects to be evaluated by the observers with yes or no in hurdles were: before the hurdle, (i) to maintain and constant speed between hurdles and no jump over; (ii) to perform a right movement of the front leg (hip flexion with bended knee); on the hurdle, (iii) to perform a right movement of the back leg (hip abduction with bended knee); (iv) to use the arms to equilibrated the body in the flight phase; and after the hurdle, (v) to do a fast movement with the front leg to contact the floor with an active metatarsus. At the end we had a score with a percentage of key aspects that the students have get right in their executions. The observers were considered appropriately trained when an inter-observer correlation coefficient between them and an expert was equal to or greater than .90. In addition, the observers recoded a random set of videotapes after the completion of the study and reached an intra-observer correlation of .98. To calculate this coefficient, the intraclass correlation coefficient and the Kappa index, following the reference values by Altman (1991), were used.

Knowledge. Knowledge of the events was measured through the use of a written test. The initial version of the test was developed by the researchers using content from a number of different manuals related to track and field (Carr, 1999; Guthrie, 2003; USA Track \& Field [USATF], 2000). The specific topics for assessment were identified following discussion with teachers who agreed that this information was an appropriate match with the Spanish curriculum documents. A panel of experts (five Doctors in Physical Activity and Sport Sciences with eight years of experience, teaching in higher education, and five Level 3 Spanish Athletics Coaches, with ten years of experience coaching youth and seniors), then validated the content as being representative of those items suggested by the physical educators. They scored (0 to 10 ) each question in relation with its accuracy, comprehension and difficulty level. The final written test consisted of 15 multi choice questions (five per event), of rules and technique of the event, and required approximately 10 minutes of student time to complete. For example in shot put, one of the questions was about the possibility to throw the ball out of the throw circle, and other was to know if s more important to do the strength with the upper or the lower body. Every question was scored with true or false, so at the end we had a total score (sum of the rights answers).

\section{Data analysis}

From the results of the pretest for the qualitative technique tests of each of the skills, three levels of student performance were established (low, average, and high). These criteria corresponded to the objectives indicated in the units for the different disciplines taught, and they were different for the students from the first and third courses. These objectives were choosen from some national (Gil, Pascua, \& Sánchez, 2000) and international coaching manuals (Hubiche \& Pradet, 1999; Seners, 2001). For example, in the shot put, it was selected six key technique points, so if a student after the skill test perfomed the six points appropiatley, he was assigned high level, if performed four, average, and if performed two, low. Mean and standard deviation scores for each of the eight classes were calculated for the skill, technical and knowledge tests. Following, a repeated-measures multivariate analysis (MANOVA) was computed. The results were grouped according to: (i) task organization (lines, circuits, or game activities), (ii) the grade level (first or third course), and (iii) skill level (low, average, or high). In studies such as this, for the student to be used as the unit of analysis, it is important to determine if an assumption of observation independence has not 
been violated. Chen \& Zhu (2001) suggest that for this to be the case, an intra-correlation of the dependent measures needs to exceed 0.10. Given that was the case with the data in the current study, the analysis was conducted with the student as the unit of analysis.

Experimental control. In an effort to increase validity, a number of factors were used which disqualified participants' scores from the final analysis. These included attendance requirements and out of school physical activity. First, students had to complete a test on all three time lines, and had to attend at least two of the three class sessions per skill to be included. Second, students who took part in five hours or more of the same skills outside the class, as measured by self-report were not included in the analysis.

\section{Results}

\section{Skill learning}

Performance measures. The outcomes of the skill execution tests are shown in Table 1, with significant findings of the ANOVA analysis presented in Table 2. The scores in Table 1 are listed as means $(M)$ and standard deviations (SD), so that the reader can make more meaningful comparisons between events. The statistical differences reported however, are from the raw data scores. That is, hurdles analysis was measured in seconds, while shot put and high jump were measured in meters.

Table 1. Means and standard deviations in Quantitative Scores across Event and Skill Levels.

\begin{tabular}{|c|c|c|c|c|c|c|c|c|c|c|}
\hline \multirow{3}{*}{ Event } & \multirow{3}{*}{ Org } & \multicolumn{3}{|c|}{$\begin{array}{l}\text { Lower skilled } \\
\qquad(n=29)\end{array}$} & \multicolumn{3}{|c|}{$\begin{array}{l}\text { Medium skilled } \\
\qquad(n=48)\end{array}$} & \multicolumn{3}{|c|}{$\begin{array}{l}\text { High Skilled } \\
\qquad(n=29)\end{array}$} \\
\hline & & pre & post & re & pre & post & re & pre & post & re \\
\hline & & $M(S D)$ & $M(S D)$ & $M(S D)$ & $M(S D)$ & $M(S D)$ & $M(S D)$ & $M(S D)$ & $M(S D)$ & $M(S D)$ \\
\hline \multirow{3}{*}{ Hurdles } & Lines & $8.12 \pm 1.0$ & $7.77 \pm .72$ & $7.91 \pm 1.0$ & $7.27 \pm .78$ & $6.82 \pm .72$ & $7.42 \pm .89$ & $6.75 \pm .70$ & $6.83 \pm .68$ & $6.96 \pm .94$ \\
\hline & Circuit & $8.61 \pm 2.1$ & $8.73 \pm 1.8$ & $7.77 \pm .91$ & $7.63 \pm 2.2$ & $7.48 \pm 2.0$ & $6.93 \pm .88$ & $6.46 \pm 1.5$ & $6.97 \pm 1.4$ & $6.84 \pm 1.2$ \\
\hline & Games & $8.44 \pm 2.3$ & $7.61 \pm 1.7$ & $7.44 \pm .92$ & $7.36 \pm .69$ & $7.16 \pm .69$ & $7.14 \pm .82$ & $6.84 \pm .80$ & $6.65 \pm .65$ & $6.65 \pm .73$ \\
\hline \multirow{3}{*}{$\begin{array}{l}\text { High } \\
\text { jump }\end{array}$} & Lines & $1.06 \pm .05$ & $1.05 \pm .05$ & $1.06 \pm .05$ & $1.14 \pm .09$ & $1.13 \pm .07$ & $1.13 \pm .07$ & $1.21 \pm .10$ & $1.23 \pm 1.1$ & $1.23 \pm 1.1$ \\
\hline & Circuit & $1.14 \pm .12$ & $1.11 \pm .11$ & $1.13 \pm .13$ & $1.18 \pm .11$ & $1.18 \pm .11$ & $1.19 \pm .10$ & $1.20 \pm .89$ & $1.23 \pm .95$ & $1.23 \pm 1.5$ \\
\hline & Games & $1.09 \pm .07$ & $1.06 \pm .05$ & $1.08 \pm .08$ & $1.14 \pm .11$ & $1.14 \pm .11$ & $1.14 \pm .11$ & $1.17 \pm .46$ & $1.20 \pm .56$ & $1.21 \pm .12$ \\
\hline \multirow{3}{*}{$\begin{array}{l}\text { Shot } \\
\text { put }\end{array}$} & Lines & $5.35 \pm 1.2$ & $5.85 \pm 1.4$ & $5.41 \pm 1.3$ & $5.70 \pm .93$ & $6.46 \pm .96$ & $6.09 \pm .69$ & $6.68 \pm 1.3$ & $7.05 \pm 1.5$ & $6.05 \pm 1.7$ \\
\hline & Circuit & $5.78 \pm 1.8$ & $5.84 \pm 1.3$ & $6.23 \pm 1.4$ & $7.17 \pm 1.9$ & $7.36 \pm 1.8$ & $7.36 \pm 1.9$ & $5.95 \pm 2.8$ & $6.54 \pm 1.4$ & $6.57 \pm 2.2$ \\
\hline & Games & $5.37 \pm 1.7$ & $5.77 \pm 1.7$ & $5.79 \pm 1.5$ & $5.44 \pm 1.4$ & $6.14 \pm 1.6$ & $5.97 \pm 1.4$ & $6.04 \pm 1.0$ & $6.67 \pm 1.1$ & $6.93 \pm 1.5$ \\
\hline
\end{tabular}

As can be seen from these data, improvement was influenced by the event and condition. Most notably, the context of practice seems to have no influence on high jump performance or for those students with higher initial skill levels. For hurdles, lower and medium skilled students seemed to gain the most in game activities, while for shot put, these same students made significant improvements after practicing in lines. 
Calderón, A.; Hastie, P.A.; Palao, J.M.; Ortega, O. (2013). The effects of task organization on skill and knowledge in physical education. RICYDE. Rev. int. cienc. deporte. 30(9), 48-59.

http://dx.doi.org/10.5232/ricyde2013.03104

Table 2. Post-hoc Analysis for Quantitative Measures.

\begin{tabular}{|l|c|c|c|l|}
\hline Variables & $F_{(3,106)}$ & $p$ & $\eta^{2}$ & Post Hoc Bonferroni \\
\hline Hurdles / Games / Lower skill & 3929 & .038 & .304 & Pre $>$ Pos; Pre $>$ Re; Pos $>$ Re \\
\hline Hurdles / Games / Medium skill & 8840 & .001 & .291 & Pre $>$ Pos; Pre $>$ Re; Pos $>$ Re \\
\hline Shot Put / Lines / Lower skill & 7216 & .005 & .445 & Pre $<$ Post; Pre $<\operatorname{Re}$ \\
\hline Shot Put / Lines / Medium skill & 7380 & .002 & .251 & Pre $<$ Post; Pre $<\operatorname{Re}$ \\
\hline
\end{tabular}

Technique measures. Tables 3 and 4 present the data for the students' performance on the technical components of the skills. Again, the data in Table 3 are expressed as means and standard deviations. With respect to hurdles, the organization of the task seemed to have no significant effect on lower skilled students, as significant improvements were made across all conditions. For medium and higher skilled students, technical performance in hurdles (just us for performance measures for the medium level students) was positively affected by game activities. Lower and medium skilled students also make improvements in their high jump technique during game play practice, but none of the practice contexts seemed to positively help higher skilled students. For the shot put, only the lower skilled students made significant improvements, and only in the lines and games practice conditions.

Table 3. Means and standard deviations in Technique across Event and Skill Levels.

\begin{tabular}{|c|c|c|c|c|c|c|c|c|c|c|}
\hline \multirow{3}{*}{ Event } & \multirow{3}{*}{ Org. } & \multicolumn{3}{|c|}{$\begin{array}{l}\text { Lower killed } \\
\qquad(n=29)\end{array}$} & \multicolumn{3}{|c|}{$\begin{array}{l}\text { Medium skilled } \\
\qquad(n=48)\end{array}$} & \multicolumn{3}{|c|}{$\begin{array}{l}\text { High Skilled } \\
\qquad(n=29)\end{array}$} \\
\hline & & pre & post & re & pre & post & re & pre & post & re \\
\hline & & $M(S D)$ & $M(S D)$ & $M(S D)$ & $M(S D)$ & $M(S D)$ & $M(S D)$ & $M(S D)$ & $M(S D)$ & $M(S D)$ \\
\hline \multirow{3}{*}{ Hurdles } & Lines & $17.4 \pm 1.2$ & $27.8 \pm 1.9$ & $28.9 \pm 2.7$ & $52.2 \pm 5.8$ & $53.3 \pm 2.0$ & $52.4 \pm 2.1$ & $83.3 \pm .00$ & $76.6 \pm 1.9$ & $73.3 \pm 1.6$ \\
\hline & Circuit & $20.5 \pm 1.3$ & $46.1 \pm 1.8$ & $46.1 \pm 2.3$ & $55.1 \pm 8.0$ & $66.6 \pm 9.0$ & $54.4 \pm 1.4$ & $83.3 \pm .00$ & $83.3 \pm .00$ & $76.6 \pm 1.3$ \\
\hline & Games & $27.8 \pm 1.0$ & $44.4 \pm 1.6$ & $51.1 \pm 2.6$ & $53.8 \pm 7.3$ & $57.5 \pm 1.4$ & $58.3 \pm 1.3$ & $83.3 \pm .00$ & $85.4 \pm 1.4$ & $83.3 \pm 8.3$ \\
\hline \multirow{3}{*}{$\begin{array}{l}\text { High } \\
\text { jump }\end{array}$} & Lines & $15.5 \pm 1.7$ & $16.6 \pm 1.6$ & $19.5 \pm 1.8$ & $55.9 \pm 8.6$ & $50.2 \pm 2.2$ & $58.7 \pm 2.9$ & $82.2 \pm 3.1$ & $70.1 \pm 1.8$ & $76.0 \pm 1.9$ \\
\hline & Circuit & $20.5 \pm 1.4$ & $23.0 \pm 2.1$ & $26.6 \pm 2.0$ & $51.0 \pm 1.6$ & $54.5 \pm 2.4$ & $56.4 \pm 2.8$ & $78.9 \pm 1.6$ & $65.3 \pm 1.0$ & $65.0 \pm 1.7$ \\
\hline & Games & $30.8 \pm 9.4$ & $38.3 \pm 2.3$ & $47.3 \pm 1.3$ & $53.1 \pm 1.1$ & $50.3 \pm 2.5$ & $59.8 \pm 3.8$ & $80.0 \pm 5.5$ & $65.5 \pm 1.7$ & $61.2 \pm 1.7$ \\
\hline \multirow{3}{*}{$\begin{array}{l}\text { Shot } \\
\text { put }\end{array}$} & Lines & $21.4 \pm 1.3$ & $25.4 \pm 1.6$ & $28.6 \pm 1.9$ & $52.2 \pm 8.6$ & $51.1 \pm 9.8$ & $50.2 \pm 1.2$ & $83.3 \pm .00$ & $83.3 \pm .00$ & $79.1 \pm 2.0$ \\
\hline & Circuit & $27.3 \pm 1.1$ & $38.9 \pm 2.0$ & $48.5 \pm 1.5$ & $51.4 \pm 1.6$ & $52.8 \pm 1.9$ & $56.9 \pm 1.5$ & $66.6 \pm 2.3$ & $55.5 \pm 1.9$ & $61.1 \pm 9.6$ \\
\hline & Games & $28.2 \pm 2.0$ & $28.6 \pm 1.5$ & $29.5 \pm 1.4$ & $53.1 \pm 2.0$ & $50.0 \pm 1.8$ & $49.2 \pm 2.1$ & $80.9 \pm 6.3$ & $59.2 \pm 2.6$ & $66.6 \pm 1.3$ \\
\hline
\end{tabular}


Calderón, A.; Hastie, P.A.; Palao, J.M.; Ortega, O. (2013). The effects of task organization on skill and knowledge in physical education. RICYDE. Rev. int. cienc. deporte. 30(9), 48-59.

http://dx.doi.org/10.5232/ricyde2013.03104

Table 4. Post-hoc Analysis for Technique Measures.

\begin{tabular}{|l|l|l|l|l|}
\hline Qualitative & $F_{(3,106)}$ & $p$ & $\eta^{2}$ & Post Hoc Bonferroni \\
\hline Hurdles / Lines / Lower skill & 9834 & .0005 & .134 & Pre $<$ Pos; Pre $<$ Re \\
\hline Hurdles / Circuit / Lower skill & 8042 & .001 & .272 & Pre < Pos; Pre $<$ Re \\
\hline Hurdles / Games / Lower skill & 10537 & .0005 & .329 & Pre < Pos; Pre $<$ Re \\
\hline Hurdles / Games / Medium skill & 6692 & .003 & .222 & Pre $<$ Pos; Pre $<$ Re \\
\hline Hurdles / Games / Higher skill & 4022 & .032 & .259 & Pos $>$ Re \\
\hline High Jump / Games / Lower skill & 15141 & .0005 & .437 & Pre $<$ Pos; Pre $<$ Re; Pos $<$ Re \\
\hline High Jump / Games / Medium skill & 3462 & .039 & .116 & Pre $<$ Re \\
\hline Shot Put / Lines / Lower skill & 3809 & .030 & .148 & Pre $<$ Pos \\
\hline Shot Put / Circuit / Lower skill & 4489 & .017 & .169 & Pre $<$ Re; Pos $<$ Re \\
\hline
\end{tabular}

Content knowledge. Table 5 shows the data for the students' performance on the knowledge tests. With regard to knowledge, students in all three conditions made significant improvements between pre-and post-test situations. Control students made no improvements. Further, only students who participated in lines retained this knowledge through the re-testing. Students in the circuits and game contexts showed some regression towards pre-test scores.

Table 5. Student Performance on the Knowledge Test.

\begin{tabular}{|l|l|l|l|l|l|l|}
\hline \multirow{2}{*}{ Organization } & Pre-Post & Pre-Re & $F_{(3,120}$ & $p$ & $\eta^{2}$ & Post Hoc Bonferroni \\
\cline { 2 - 7 } & $M$ & $M$ & & & & \\
\hline Lines & 15.9 & 17.6 & 21737 & .0005 & .171 & Pre $<$ Pos \\
\hline Circuit & 15.3 & 12.8 & 22389 & .0005 & .175 & Pre $<$ Pos \\
\hline Games & 7.6 & 5.4 & 7216 & .001 & .064 & Pre $<$ Pos \\
\hline
\end{tabular}

\section{Discusión}

The results from this study corroborate the suggestions by Ashy, Lee, \& Landing (1988). Buck, Harrison, \& Brice (1991), Silverman (1985), Silverman et al., (1998), and Silverman, Devillier \& Ramirez (1991) to adapt the proposed tasks to the skill level of the students and to avoid plan only one task for all students. Essentially, the results of this study confirm that, indeed, one size does not fit all. The disparate results across skill levels and athletic events showed that there is no "silver bullet" in terms of improving skills and technique (there is no one best single answer for organizing classes that would apply in all situations). This discussion will examine the histories of the various students and their interactions with the events. For high skilled students, there was no evidence in performance improvement over the study, regardless of the event or the task condition. This factor is compounded when we consider that those who were athletics participants were excluded from the analysis. Consequently these were "novice" athletes but despite that, were still more skilled. The best possible explanation for these outcomes is that the unit length was insufficient for the development of the more refined skills needed for these students to show improvement. 
This has quite implications for many more highly skilled students in physical education. In many countries, teachers are often reluctant to commit to longer units of instruction, claiming (most often without any empirical evidence), that students will become bored with prolonged instruction. However, this claim is disputed from a number of research programs such as Sport Education (Hastie, 2000) and the extended badminton studies of Tjeerdsma, Rink, \& Graham (1996) who showed no evidence of boredom when students are actively engaged in improvement. What is usually a better indicator of student boredom in physical education is that the content and pedagogy is irrelevant and does not excite or stimulate adolescents who outside of school are engaging with radically new cultural conditions and bring with them new sensibilities, needs, and expectations about physical activity (Tinning \& Fitzclarence, 1992).

While the experience of the high skilled students could best be described as "one size fits none", for the lower and middle range skilled students, improvement in skill performance and technique were dependent upon the event practiced. For both groups, practice in the closed skill of shot put was most beneficial when done in lines. This set up allowed for a higher number of repetitions together with more specific and available feedback from the teacher. With the environment being more controlled (significantly more than the circuits and game formats), the teacher was able to provide students with a consistent environment of repetitions. Given that performance during the early state of skill practice is usually more effective under blocked-practice conditions than under random-practice conditions (Russell \& Newell, 2007; Schmidt \& Wrisberg, 2008), this organization seems suitable. This notion is supported also by Granda, Barbero \& Montilla (2008) who showed block group practice was more effective when learning closed skills in soccer.

However, participation in game activities provided the best results. In these classes, students practiced hurdles in games of chasing and fleeing. This context closely resembles what Rink (2005) refers to an environmentally designed task, a situation that exists when the teacher changes the physical arrangements for the task to elicit the pattern of coordination desired. That is, environmental design occurs when the teacher manipulates the task conditions to both change the student's perception of the action goal (i.e., what they are trying to do in the task) as well as to constrain environmentally the action in a manner that encourages the students to "self organize" a more mature pattern (Sweeting \& Rink, 1999). This method has been found to be effective with novice learners. Rather than set up a series of isolated hurdles tasks (as was the case in lines and circuits), the environmental design of the game situations required students to run fast over the hurdles in an applied situation (i.e., trying not to get caught). The superior performance by all students in this context again reinforces the well known conclusion about specificity in transfer of training (Schmidt \& Wrisberg, 2008) that motor performance is superior when practice conditions match the conditions in which the motor skills will be used.

With respect to high jump performance, while none of the task organizations had a positive effect, practice in lines was the least detrimental to learning. Moreover, the significant variance in the scores across groups suggests problems with the measurement of the performance. That is, in this study, high jump skill was recorded as only the success or not of a jumper over a pre-determined height. With regard to technical performance, like hurdles, the most improvement was in games. Again, the environmental design of the high jump tasks may have helped students develop the necessary techniques more effectively than in the more structured manner of lines. It is also true that of the three skills, the high jump compared to simpler skills (hurdles and shot put), is likely require more practice and more fine-tuning of technique before improvements are shown; so the current results likely apply only to simpler 
sport skills whose technique is more readily learned, or which is already part of the child's movement repertoire.

It is also important to note that there is another key variable, which has an effect in learning, as other studies report (Ashy et al., 1988; Silverman, 1985). It should be take in account that circuits and games provide significantly more practice repetitions, but maybe the quality of those repetitions is somewhat compromised (at least when compared with practice in lines) because of the less control of the teacher. As Hastie, Calderón, Palao, \& Ortega (2011), and Calderón, Palao, \& Ortega (2005) reported, organization in lines provides a more favorable situation for active supervision and feedback by the teacher, this format may be more suitable for students of lower level or beginning students. On the other hand, when students have an average or high skill level, circuits and games seem to be more suitable because it allows more autonomy and involves more students (Calderón et al., 2005; Hastie et al., 2011).

Lastly, when examining the results of the knowledge tests, the students improved in their comprehension of the key technical aspects of the skills across all levels of task organization. However, it is doubtful whether the students might be able to apply this knowledge in future contexts given the short length of the units. While this assumption was not tested in this study, it is certainly worth considering in future research.

\section{Conclusion}

This study provides some support in an applied condition for the claim of Guadagnoli \& Lee (2004) that a performer's skill level and certain practice conditions contribute to defining the functional difficulty of a task, and that these two characteristics are critical during the motor learning process. Those differential effects were found according to skill level and the design of the task demonstrates that teachers need to be aware of the way in which students are asked to practice. What is perhaps more significant, however, are the quick losses of the performance gains in short times after the units.

Put best, "the superficial introduction of a skill without opportunities to more fully develop the skill would be contraindicated and, perhaps in the long run, a waste of time” (Sweeting \& Rink, p. 228). As a number of authors note, a lack of experience and a lack of ability are by far the most common reasons for students not wanting to participate in sporting activities (Feltz \& Brown, 1984; Tjeerdsma, Rink, \& Graham, 1996). Having skill correlates with enjoyment, which in turn enhances participation. As Carlson (1995) has noted, if one of the major goals of physical education is for students to lead active lifestyles, then the development of skill and positive experiences are significant contributors. By consequence, it is essential for physical education teachers to consider the skill level of their students and the type of task organization that they are going to utilize in their sessions, among other important variables (quality, quantity, feedback, teaching style, etc,), in order to allow the learning process to develop optimally. 


\section{References}

Altman, D. G. (1991). Practical statistics for medical research. New York: Chapman and Hall.

Ashy, M. H.; Lee, A. M.; \& Landing, D. K. (1988). Relationships of practice using correct technique to achievement in a motor skill. Journal of Teaching in Physical Education, 7, 115-120.

Barreiros, J., Figueiredo, T., \& Godinho, M. (2007). The contextual interference effect in applied settings. European Physical Education Review, 13(2), 195-208.

Behar. J. (1993). Sesgos del observador. En M. T. Anguera (Ed.), Metodología observacional en la investigación psicológica (pp. 27-76). Barcelona: Promociones y Publicaciones Universitarias.

Buck, M.; Harrison, J. M.; \& Brice, G. R. (1991). An analysis of learning trials and their relationship to achievement in volleyball. Journal of Teaching in Physical Education, 10, 134-152.

Calderón, A.; Palao, J. M., \& Ortega, E. (2005). Incidencia de la forma de organización sobre la cantidad y la calidad de práctica, el feedback impartido y la percepción de motivación en la enseñanza de habilidades atléticas. Cultura, Ciencia, y Deporte, 1, 145- 155.

Carlson, T. B. (1995). We hate gym: student alienation from physical education. Journal of Teaching in Physical Education, 14, 467-477.

Carr, G. A. (1999). Fundamentals of Track and Field (2nd ed.). Champaign, IL: Human Kinetics.

Chen, A., \& Zhu, W. (2001). Revisiting the assumptions for inferential statistical analysis: a conceptual guide for pedagogy research in physical education. Quest, 53, 418-439.

Feltz, D., \& Brown. E. (1984). Perceived competence in soccer skills among young soccer players. Journal of Sport Psychology, 6, 385-394.

Gil, F., Pascua, M., \& Sánchez, R. (2000). Manual Básico de Atletismo. Madrid: Real Federación Española de Atletismo.

Granda, J.; Barbero, J. C., \& Montilla, M. (2008). Effects of different practice conditions on acquisition, retention, and transfer of soccer skills by 9 -year-old schoolchildren. Perceptual and Motor Skills, 106, 447-460.

Guadagnoli, M. A., \& Lee, T. D. (2004). Challenge point: A framework for conceptualizing the effects of various practice conditions in motor learning. J ournal of Motor Behavior, $36,212-224$.

Guthrie, M. (2003). Coaching track and field successfully. Champaign, IL: Human Kinetics.

Hastie, P. A. (2000). An ecological analysis of a Sport Education season. Journal of Teaching in Physical Education, 19, 355-373.

Hastie, P. A.; Calderón. A.; Palao. J. M., \& Ortega, E. (2011). Quantity and quality of practice: interrelationships between task organization and student skill level in physical education. Research Quarterly for Exercise \& Sport, 82(4), 784-787.

Hubiche, J. L., \& Pradet, M. (1999). Comprender el atletismo. Su práctica y enseñanza. Madrid: Inde.

Human Kinetics ( Producer). (1999a). Jumps. [video]. Champaign: Human Kinetics.

Human Kinetics ( Producer). (1999b). Throws. [video]. Champaign: Human Kinetics. 
Metzler, M. W. (2005). Instructional models for physical education. Scottsdale, AZ: Holcomb Hathaway.

Piasenta, J. (2000). Aprender a observar. Barcelona: Inde.

Renshaw, I., Chow, J., Davids, K., \& Hammond, J. (2010). A constraints-led perspective to understanding skill acquisition and game play: a basis for integration of motor learning theory and physical education praxis?, Physical Education \& Sport Pedagogy, 15(2), 117-137.

Rink, J. E. (2005). Teaching physical education for learning (5th ed). Boston: McGraw Hill

Rink, J. (2003). Effective instruction in physical education, en S.J. Silverman \& C.D. Ennis (Eds.), Student learning in physical education: Applying research to enhance instruction (pp. 165-186). Champaign. IL: Human Kinetics.

Russell, D. M. \& Newell, K. M. (2007). How persistent and general is the contextual interference effect? Research Quarterly for Exercise and Sport, 78, 318-327.

Schmidt, R. A., \& Wrisberg. C. A. (2008). Motor learning and performance: A situationbased learning approach. Champaign. IL: Human Kinetics.

Seners, P. (2001). Didáctica del Atletismo. Inde: Madrid.

Siedentop, D., \& D. Tannehill. 1999. Developing teaching skills in physical education. 4th ed. Mountain View, CA: Mayfield Publishing Company.

Silverman, S. (1985). Relationship of engagement and practice trials to student achievement. Journal of Teaching in Physical Education, 5, 13-21.

Silverman, S. (1994). Research on teaching and student achievement. Sport Science Review, 3, 83-90.

Silverman, S. (2005). Thinking long term: Physical education's role in movement and mobility. Quest, 57, 138-147.

Silverman, S.; Devillier. R.; \& Ramirez. T. (1991). The validity of academic learning time in physical education (ALT-PE) as a process of measure of student achievement. Research Quarterly for Exercise \& Sport, 62, 319-325.

Silverman, S.; Kulinna, P., \& Crull, G. (1995). Skill-related task structures, explicitness, and accountability: relationships with student achievement. Research Quarterly for Exercise \& Sport, 66, 32-44.

Silverman, S.; Mays, A., \& Subramaniam, P. (1998). Task structures, student practice, and skill in physical education. The J ournal of Educational Research, 91. 298-306.

Silverman, S.; Tyson, L., \& Marrs, L. (1988). Relationships of organization, time, and student achievement in physical education. Teaching and Teacher Education, 4, 247257.

Sweeting, T., \& Rink, J. (1999). Effects of direction instruction and environmentally designed instruction on the process and product characteristics of a fundamental skill. J ournal of Teaching in Physical Education, 18, 216-233.

Tjeerdsma, B. L.; Rink, J. E., \& Graham, K. C. (1996). Student perceptions, values, and beliefs prior to, during, and after badminton instruction. Journal of Teaching in Physical Education, 15, 464-476.

Tinning, R., \& Fitzclarence, L. (1992). Postmodern youth culture and the crisis in australian secondary school physical education. Quest, 44, 287-303.

USA Track \& Field, (2000). USA Track and field coaching manual. Champaign. IL: Human Kinetics. 